\title{
Interactivity during Covid-19: mediation of learner interactions on social presence and expected learning outcome within videoconference EFL courses
}

\author{
Daniel Bailey $^{1}$ (D)
}

Received: 5 June 2021 / Revised: 3 October 2021 / Accepted: 6 October 2021 /

Published online: 15 October 2021

(C) Beijing Normal University 2021

\begin{abstract}
Social presence in education pertains to the connectedness students have with one another and is highly indicative of course satisfaction and performance. Further, social presence fosters motivation and promotes opportunities for collaboration, therefore, considered a critical factor in influencing second language acquisition. In the context of emergency remote online courses due to Covid-19, this study investigates the role of social presence in relation to learner interactions and learning outcome beliefs. To this end, this research is interested in learning how social presence influences learner-learner, learner-instructor, and learner-content interactions within videoconference-supported EFL classes. This study also identifies the mediating effects learner interactions have on the relationship between social presence and expected learning outcomes. This cross-sectional questionnaire study surveyed 547 South Korean university EFL students and data were analyzed using structural equation modeling to measure direct and indirect relationships among the variables of interest. The findings indicate that students' levels of social presence positively influenced rates of interactions with their classmates, the instructor, and course content. Results further provide insight pertaining to the academic achievement students expect when participating in videoconferencing courses, and how this relationship between social presence and academic learning outcome is distinctly mediated by learner-instructor and learner-content interactions. Findings give insight into the sorts of activities and practices instructors can employ; for instance, EFL instructors are recommended to clearly assess learner-learner interactions if such interactions are to have a significant influence on course outcome beliefs when using videoconferencing tools effectively in the post Covid-19 era.
\end{abstract}

Daniel Bailey

dbailey0566@kku.ac.kr

1 Department of English Language and Culture, Konkuk University (Glocal Campus), Hillstate Bldg. 108 \#603, Yeonsu-dong, Chungju 27353, South Korea 
Keywords Videoconference course $\cdot$ Zoom $\cdot$ Learner interactions $\cdot$ Instructor interactions $\cdot$ ESL/EFL $\cdot$ Academic learning outcome $\cdot$ Social presence $\cdot$ Covid-19

\section{Introduction}

In the midst of the Covid-19 pandemic, courses were forced online with many classes taught using live videoconference platforms. During this period of online teaching, students had to quickly learn how to navigate videoconferencing classes susceptible to technical problems like broken audio, frozen screens, and slow Internet connection. For conversational English classes in South Korea, synchronous communication using videoconferencing platforms were chosen over stand-alone lesson videos because synchronous communication with students provides an opportunity for face-to-face second language (L2) speaking and listening practice. However, these videoconferencing platforms only allow for one speaker at a time and prevent the instructor from concurrently observing more than one sub-conference room (e.g., Zoom breakout room). In classes that use English as a foreign language (EFL), this lack of instructor observation of student activities is problematic since students may fall back on using their first language (e.g., Korean) or avoid speaking altogether. In such communication classes, social presence and learner interactions are critical for developing experiential knowledge and are considered contributing factors to second language acquisition (SLA). Therefore, understanding how reported levels of social presence relate to online learner interactions and the consequential influence those interactions have on course outcomes in EFL communication is an important step to designing classes conducive to ongoing active engagement.

Social presence is considered a key antecedent to language learning and posited here to be beneficial for EFL students in South Korea who are expected to practice conversational English. Ubon and Kimble (2003) acknowledge that social presence encourages learning motivation and promotes opportunity for collaborative learning, both essential components for the communication expected by good language learners (Rubin, 1975). Contributing to collaboration and overall engagement, social presence can help explain academic outcomes within learning environments supported by videoconferencing software.

A growing amount of research has concentrated on synchronous computer-mediated communication in language learning using videoconference technology (de Oliveira \& Esteve-González, 2020; Eslami \& Kung, 2016; Kim, 2014; Lenkaitis, 2020). Such synchronous communication refers to the online interactive transfer of data, video, or text, between two or more learners concurrently through a computer or mobile device. An advantage synchronous communication with videoconferencing affords is the capacity to transmit information through non-verbal cues. In EFL, non-verbal cues play a role in compensation strategies for both the speaker and listener. Through facial expressions, the instructor can convey the importance of an activity, assignment, or date. Likewise, the instructor can interpret a student's level of understanding through how much confidence or apprehension they exhibit with body language. To this end, success in a videoconferencing classroom may depend on a student's willingness to interact and exposure to opportunities to interact. 
To date, online class interaction research typically measures either the quantity or quality of the interactions, leaving a need for more literature attempting to identify how these different interaction types help explain the relationships between outside antecedents to course outcomes like academic achievement beliefs (Bernard et al., 2009), especially in videoconference courses like conversational English that are typically taught face-to-face but were transferred online due to social distancing measures implemented during the Covid-19 crisis.

Concerning second language acquisition, learner interactions are the foundation of several learning theories (Krashen, 1982; Swain, 1985; Vygotsky, 1978). The three types of class-related interactions that are influential to perceived academic learning accomplishments, and of concern here, are learner-learner interactions (LLI), learner-instructor interactions (LII), and learner-content interactions (LCI; Kang \& Im, 2013; Moore, 1989). These classroom interactions elevate the degree students become aware of one another, directly influencing their cognitive and affective aspects of learning (Akcaoglu \& Lee, 2018). Most research on interactions in online learning have focused on fully online asynchronous communication or a combination of both asynchronous online and face-to-face blended learning, while much less research has investigated interactions with courses that use both videoconferencing and LMS features, a void of concern addressed in the current study.

Following the community of inquiry framework, this study posits higher levels of social presence among learners increases the frequency of classroom interactions, and consequently, levels of learner satisfaction. Students dynamically participate and trust each other in social activities, and through their shared trust build deeper levels of shared learning experiences. In online spaces, the frequency and types of interactions, either with the learner, instructor, or content, may influence the relationship between social presence and academic performance. The crux of the current study is to illuminate these direct and indirect relationships among social presence, learner interactions, and expected learning outcome. In hopes to accomplish these aims, the following research questions are asked.

Research Question 1 What are the influences of social presence on expected learning outcome and learner interactions in videoconference EFL courses?

Research Question 2 How do learner interactions mediate the relationship between social presence and expected learning outcome in videoconference EFL courses?

\section{Literature review}

\section{Theoretical framework}

The theoretical framework for this research is based on the work by Garrison (2017), who established a connection between the community of inquiry (CoI) and distance education. The CoI framework is grounded on the learners' capacity to build their 
social presence within face-to-face or online environments. The success behind integrating the CoI framework when designing and implementing online courses is related to the critical component of social presence within higher education (Garrison \& Vaughan, 2008). Social presence has been found to have a positive effect with foreign language participation in Zoom breakout rooms (i.e., sub-conference rooms). Through interview and observation analysis, Rakushin-Lee (2021) reported on increased levels of social presence among a group of EFL students $(n=25)$ made possible through Zoom breakout rooms. Through group activities in sub-conference Zoom sessions with breakout rooms, students reported to enjoy the opportunity to interact with classmates, talk face to face, and practice communication skills, all fostering a heightened sense of social presence (Rakushin-Lee, 2021).

\section{Social presence and learner interactions}

Social presence is defined as a student's propensity to feel connected with classmates in the learning environment and is recognized as a strong predictor of positive academic outcomes related to cognitive gains (Stewart, 2019). Empirical literature indicates that social presence is positively associated with increased levels of interactions (Oyarzun et al., 2017; Tu \& McIsaac, 2010). Moreover, these reported relationships emanating from learner interactions result in high levels of course satisfaction (Song et al., 2016), which is echoed by Cornelius-White's (2007) meta-analysis connecting learner interactions to positive academic outcomes. Social presence as it pertains to connectivity to others is an important component of higher education practice (Kim \& Ketenci, 2019) and, overwhelmingly, research has reported that online classroom interactions facilitate course satisfaction and a sense of community (Chatterjee \& Correia, 2020; Zhu, 2012).

Social presence and associated interactions are the crux to several second language acquisition theories including Krashen's input hypothesis (1982), Vygotsky's sociocultural theory (1978), and Swain's comprehensible output hypothesis (Swain, 1985). An underlying factor with these theories is the collaborative behavior students are expected to exhibit to develop experiential knowledge with the target language (e.g., English). Heightened levels of social presence within a community of inquiry contribute to more interactions with peers, their instructor, and content (e.g., assignments, dictionaries, and online learning systems). Consequently, EFL students with a high level of social presence are more likely to share experiences, collaborate, and construct knowledge in the second language.

\section{Learner interactions and academic learning expectations}

Increased levels of learner interactions have positive effects on academic achievement and learning satisfaction (Oyarzun et al., 2017). In the EFL context, classroom interactions contribute to experience with the target language and are a beneficial characteristic of immersive language programs (Bolton, 2008). The use of videoconferencing platforms to support learner interactions, even prior to Covid-19, supported live online EFL classes (Michel \& Cappellini, 2019; Rassaei, 2017) and were 
deemed beneficial by students (Ding, 2020; Robertson \& Piotrowski, 2019). When videoconferencing, agentic engagement, such as asking questions to the instructor during a videoconference class, helps explain the relationship between collaborative language learning orientation and academic learning expectations (Bailey et al., 2021), and is considered a crucial type of interaction that contributes to improved learning outcome (Dennen et al., 2007).

The subsets of interaction types, including learner-instructor, learner-learner, and learner-content, distinctly influence course outcome; however, these influences vary depending on the mode of communication and platform for instruction. Regarding these interaction types, Alqurashi (2019) found learner-instructor interactions critical for perceived learning, indicating the amount of contact between the students and the instructor is a necessary component of a successful online course. Therefore, the presence of the instructor and instructional communication had a significant impact on students' perceived outcomes in comparison to learner-learner and learner-content interactions (Kang \& Im, 2013). Likewise, Kuo et al. (2013) investigated the relationship between learner-instructor interactions and course satisfaction on a group of 111 undergraduate students with results indicating high positive correlation and found learner-instructor interactions were associated with elevated levels of perceived learning in addition to feelings of course satisfaction. A key factor in student success is the regularity of contact between the instructor and the students (Dennen et al., 2007).

In second language acquisition theory and practice, greater amounts of online learner-learner interaction are expected among students if more effective learning is to occur (Kara, 2020; Oyarzun et al., 2018; Swain \& Lapkin, 1998). Students should be given chances to construct knowledge collaboratively because increased social participation is indicative of cognitive engagement (Ouyang \& Chang, 2019). The indirect relationship between social presence and academic outcome may further be influenced by learner-learner interactions, especially in conversational English courses where communication among class members contributes to the course grade (Crosthwaite et al., 2015). Further, an increase in learner-learner interaction have been associated with heightened levels of satisfaction which positively influenced academic outcomes including class grade and self-assessment (Oncu \& Ozdilek, 2013). Shackelford and Maxwell (2012) measured the influence nine types of learner-learner interactions have on connectedness in a classroom community and found that all measures positively predicted social presence, with sense of community having the highest correlations for collaborative group projects, and self-disclosure of personal experiences. Generally, past studies found learner-learner interaction yields higher satisfaction than other forms of interactions, suggesting such learner interactions lead to improved learning outcomes (Kuo et al., 2013).

Not all studies place high levels of class interaction in a positive light (Bernard et al., 2009; Grandzol \& Grandzol, 2010; Tu \& McIsaac, 2010). Past research has revealed that the benefits of online class interaction might be exageraged (Oyarzun et al., 2018). In some cases, positive learning outcomes are not manifested through learner-learner interactions (Lowenthal \& Dunlap, 2018; Oyarzun et al., 2018). For instance, when students are obligated to engage one another in classroom settings, their interactions may contribute to a decrease in student performance (Kuo et al., 
2014; Oyarzun et al., 2018). Students who are asked to participate in group activities at times perceive the interactions with one another as cumbersome, which causes some amount of distress (Kuo et al., 2014). Contrarily, when interactions are voluntary, students are more satisfied with their courses, leading to a more positive class outcome (Bray et al., 2008). The influence of learner interactions must be considered in the context of the course. Factors, including learning objectives and channels of communication, contribute to outcome expectations and course satisfaction. For instance, with a sample of 1786 students attending four massive open online courses, Gameel (2017) found that learner-content interactions were most predictive of course satisfaction, while learner-learner and learner-instructor had no effect.

\section{Social presence and academic learning expectations}

Social presence in online learning has been extensively explored (Kim et al., 2016), however, the literature pertaining to the relationship between social presence and academic outcomes in evolving online learning communities needs attention (Kaul et al., 2018). Expected learning outcomes are a main indicator of course evaluation (Wright et al., 2006), highly correlate with course grades (Rockinson-Szapkiw et al., 2016), and influence the recursive process of course design, delivery and evaluation (Alavie et al., 2002). Moreover, academic learning expectations refer to the beliefs that a student can successfully master how to accomplish a given task (Bong \& Skaalvik, 2003), and consequently achieve a positive learning outcome. This expectation belief can be partly defined as onen's confidence in their ability to achieve intended results in an academic situation (Bandura, 1997).

Further benefits associated with social presence through online interactions with others include interactive communication (Ishtaiwa \& Aburezeq, 2015), multimodal accessibility (Ching \& Hsu, 2013), and improvement in the learning process (Baker $\&$ Moyer, 2018). Conversely, negative consequences with a lacking CoI result in a diminished level of social presence. In such cases, students who do not enjoy social interactions for reasons including shyness and high levels of communication apprehension, feel less connected with their more social counterparts (Cortese \& Seo, 2012; Giannopoulos et al., 2008; Jin, 2010; Kim et al., 2013). Such instances of passivity provide evidence that decreased levels of social presence are indicative of less motivation to interact with others.

More exploration is required to ensure the social presence component of the CoI framework captures the more nuanced components of specific educational practices, including the effects of course planning and the degree of engagement of course participants in videoconference settings. To this end, Stewart (2019) calls for research to draw attention on $\mathrm{CoI}$ elements, including social presence, that specifically pertain to interactions influencing students' development.

\section{Proposed mediation model}

This proposed research suggests that the relationship between learner interactions and academic learning expectations can be better understood by adding three 
levels of mediation, learner-learner, learner-instructor, and learner-content interaction. These interaction types refer to proactive involvement in classroom settings that contribute to a beneficial learning environment (Dennen et al., 2007; Kara, 2020; Oyarzun et al., 2018) and can be further defined as constructive contributions to the flow of the instruction they receive. In other words, the interactions a student experiences during videoconferencing courses contribute to their personal academic outcome.

Taking all aforementioned factors into consideration, this study aims at filling the research gap by capturing the relationships among social presence, interaction type, and perceived learning outcome during the Covid-19 pandemic. With the inclusion of learner-learner, learner-instructor, and learner-content interactions as mediating variables, we can attain a better understanding of how classroom interactions affect the relationship between social presence and academic learning expectations by separating the total influence (Path c') into direct (Path c) and indirect effects (Paths a1 and b1; Paths a2 and b2; and Paths a3 and b3). This proposed mediation model is illustrated in Fig. 1.

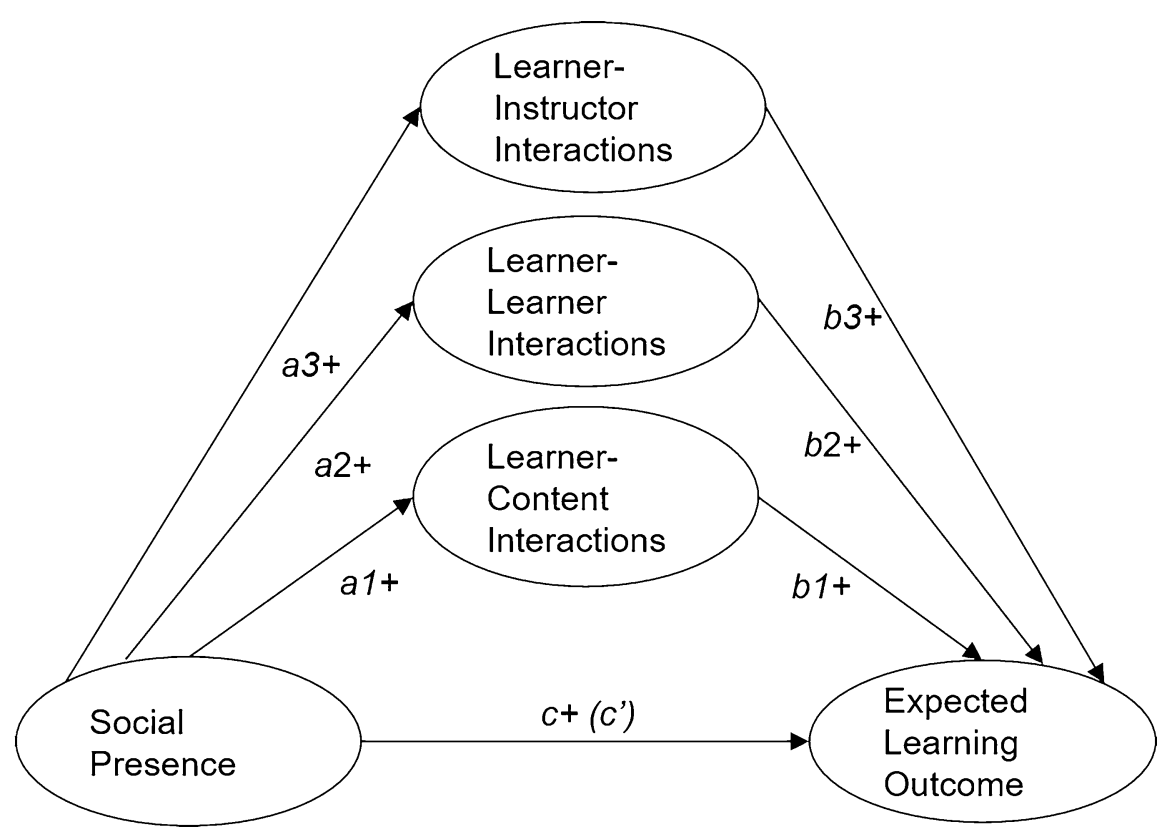

Fig. 1 Illustration of the proposed mediation model 


\section{Methods}

\section{Objective}

This quantitative research study used a cross-sectional survey design to investigate the direct and mediating effects of learner interactions on the relationship between social presence and expected learning outcome within a videoconference EFL course. The purpose of a cross-sectional study is to analyze data from a representative portion of the population at a specific period. In the case of the present study, the period of interest occurred during forced online courses due to Covid-19. Being one of the first countries reporting a Covid-19 outbreak, South Korea transferred courses online early, with many schools supplementing brick-and-mortar classrooms with a videoconferencing component. In the current study, students were attending their third semester of fully online conversational EFL courses using the Zoom videoconference software.

\section{Participants}

A snowball sampling technique was used to recruit EFL native English-speaking instructors to survey their full-credit conversational Zoom English classes resulting in a total of 10 professors with each having at least two years of online teaching experience, including the first two semesters of emergency remote classes due to Covid-19. In all, 38 classes were surveyed consisting of 547 participants. Students attended two South Korean universities, one in South Korea's capital city of Seoul (26 classes, $n=330$ ) and one from a central country-side province (12 classes, $n=217)$. The English conversational classes consisted of 270 female and 277 male university students with majors including nursing, trade, business administration, engineering, education, chemistry, psychology, tourism, biology, English, Chinese, and Russian. Student demographic data collected in the survey included age, gender, online learning experience, and self-reported L2 proficiency.

\section{Materials}

\section{The course setting}

During Covid-19, the recruited EFL instructors used the videoconferencing platform Zoom for the synchronous portion of their conversational EFL courses. In these courses, the students were immersed in an English-only speaking classroom to practice English communication skills including speaking, writing, listening, and reading. Successful learning outcomes in EFL classes, such as high English proficiency levels, are attributed to English medium instruction (Bolton, 2008). Therefore, students were encouraged and often required to only use English when talking to one another. With Zoom, the instructors acted as the host during live videoconference sessions. Smaller breakout rooms were used for independent partner and 
group activities. Within Zoom breakout rooms, students participated in partner and group activities including student-led discussions, role-play activities, storytelling, and informal presentations. Other activities, either done in groups or the class as a whole, included presentations, reading aloud, listen and repeat (shadow talking), and group-quizzes (e.g., completing a Google Form quiz together as a class).

In addition to using Zoom for the live videoconference portion of class, instructors had an asynchronous component to their course. Asynchronous activities with the course learning management system (LMS; Moodle or Blackboard) were assigned to the students as homework. A series of meetings with the recruited instructors provided some insight into the types of LMS activities students completed. These activities included paragraph and essay writing tasks, scriptwriting tasks, creative writing activities, business emails, self-disclosure blogs, and picture prompts.

\section{Study questionnaire}

The study administered a five-scale questionnaire, measuring social presence, learner-learner interactions, learner-instructor interactions, learner-content interactions, and self-efficacy for academic outcome (see Table 1). Items for the social presence component were taken from Rovai's (2002) instrument to measure classroom community. Items 11 and 12 added the phrase, "in the videoconference EFL class" to Rovai's (2002) original wording to fit the setting of the current study. Items for the learner-learner, learner-instructor, and learner-content interaction components were taken from Moore's (1989) framework of LMS interactions. For item 15 in the learner-instructor interaction scale and items 22, 24, and 25 in the learnerlearner interaction scale, the phrase, "in this videoconference EFL class" was added to fit the context of the study. Items measuring academic learning perceptions were influenced from previous academic self-efficacy studies (Artino \& McCoach, 2008; Bong \& Skaalvik, 2003; Pintrich et al., 1993) and modified to fit the EFL learning objectives within the videoconference-supported EFL course. An original item from Bong and Skaalvik's (2003) self-efficacy for learning scale states, "I can understand well even if the teacher presents complex materials in class" while a modified version reads, "I can identify the main issues covered in my videoconference EFL class." Likewise, Pintrich et al.'s (1993) self-efficacy for learning states, "I'm confident I can understand the basic concepts taught in this course," while the modified version reads, "I can fully understand the basic concepts of the content taught in my videoconference EFL class."

Table 1 lists items within their respective scales. Items were scored on a fivepoint Likert scale ranging from strongly disagree (1) to strongly agree (5). Regarding internal reliability, Cronbach alpha scores for self-efficacy of expected learning outcome, social presence, learner-instructor interactions, learner-learner interactions, and learner-content interactions were $0.91,0.90,0.82,0.77$, and 0.79 , respectively.

Items were translated from English to Korean by a professional Korean translator with a graduate degree in translation studies and over 15 years of professional experience in translating Korean and English. A second translation specialist with 
Table 1 Survey items for study scales

Self-efficacy of learning expectations

1

2

3

4

\section{Social presence}

5

6

7

8

9

10

11

12

Learner-instructor interactions

13

14

15

16

17

18

19

\section{Learner-learner interactions}

21

22

24

25

Learner-content interactions

26

27

28
I can fully understand the basic concepts of the content taught in the videoconference EFL class

I can identify the main issues covered in the videoconference EFL class

I can clearly communicate the subject in the videoconference EFL class

I can draw a general conclusion by synthesizing the facts learned in the videoconference EFL class

I feel that the students in this course are caring for each other I feel connected with other people in this process

I do not feel isolated in this course

I feel that I can rely on others in this course

I feel confident that others will support me

Online communication is excellent for social and classroom interaction

It is comfortable to interact with other participants in the videoconference EFL class

It's easy to chat with others in the videoconference EFL class

The instructor encouraged me to actively participate in the lecture discussions

The instructor provided feedback on my assignments or tests

I was able to actively communicate with the instructor during the videoconference EFL class

The instructor treated me as an individual student

The instructor periodically informed me of my learning progress

The instructor periodically informs the students of the individual learning progress

Through weekly assignments, the instructor asked students about the content of the class

While I am learning, I feel comfortable and belong with other students

I was able to share my learning experiences with other students

I was able to communicate with other students in this videoconference EFL class

It was more helpful for me to actively communicate with my fellow students outside of the lecture

This lecture encouraged me to participate in small group activities during the videoconference EFL class

I received peer feedback during the videoconference EFL class

I check the lecture materials through the class LMS

I check the announcements through the class LMS

I use the discussion board on the class LMS 
Table 1 (continued)

\begin{tabular}{ll}
\hline 29 & I check the feedback on the class LMS \\
30 & I provide feedback through the class LMS \\
31 & I check external resources and links through the class LMS \\
32 & I participate in online discussion forums through the class LMS \\
33 & I submit my assignments through the class LMS \\
\hline
\end{tabular}

5 years of experience reviewed the translated version and differences were identified, discussed, and resolved.

\section{Procedures}

The questionnaire was administered to students on their $10^{\text {th }}$ week attending their fully online videoconference classes. Students were told that the questionnaire pertained to their experience with videoconference conversational English classes and were given $25 \mathrm{~min}$ to finish the survey during class time under instructor supervision. The survey was delivered using Google Forms (forms.google.com), and students were informed that their answers would be anonymous and password protected.

\section{Data analysis}

For data screening and to calculate descriptive analysis, the statistical package for social science (SPSS; Version 25) was used. Pearson correlation and mean scores were calculated to provide an initial view of the survey results. Demographic variables (e.g., gender, age, and L2 proficiency) were added to the correlation table to give additional context to the relationships. Analysis of moment structure (AMOS; version 27) was then used for confirmatory factor analysis and to test the proposed mediation model.

\section{Data screening}

Linear regression analysis of the study variables was used to save Mahalanobis and Cook's distance values to identify outliers in which twelve existed and were removed, leaving 547 completed surveys. Regarding kurtosis and skewness, normal distribution was observed with kurtosis values within the -2 and +2 range and skewness values within the -1.96 and +1.96 range, indicating acceptable levels of normal univariate distribution (George \& Mallery, 2010). Further, none of the correlation coefficients between variables exceeded 0.70 as shown in Table 2 , providing evidence of no multicollinearity issues in the data (Tabachnick \& Fidell, 2001). Next, the study examined variable inflation factors (VIF) and found no VIF greater than two which is below the recommended threshold of 10. The Kaiser-Meyer-Olkin (KMO) was 0.987 and Bartlett's Test of Sphericity was 7675.102 $(\mathrm{df}=231, p<0.001)$, within acceptable ranges (George \& Mallery, 2010). 
Table 2 Correlations and mean scores of study variables

\begin{tabular}{lllllllllll}
\hline & & 1 & 2 & 3 & 4 & 5 & 6 & 7 & 8 & 9 \\
\hline 1 & Age & & & & & & & & & \\
2 & Gender & -.068 & & & & & & & & \\
3 & Online Exp & $.326^{* *}$ & .072 & & & & & & & \\
4 & L2 Prof & -.020 & $.121^{* *}$ & $.175^{* *}$ & & & & & & \\
5 & SP & .006 & $.101^{*}$ & -.065 & .006 & & & & & \\
6 & ELO & -.008 & $.078^{*}$ & -.041 & $.400^{* *}$ & $.310^{* *}$ & & & & \\
7 & LLI & .036 & $.098^{*}$ & .074 & $.119^{* *}$ & $.587 * *$ & $.293^{* *}$ & & & \\
8 & LII & $.079 *$ & -.016 & -.038 & .072 & $.408^{* *}$ & $.468^{* *}$ & $.419^{* *}$ & & \\
9 & LCI & -.050 & $.117^{* *}$ & -.057 & $.081^{*}$ & $.219 * *$ & $.344^{* *}$ & $.196^{* *}$ & $.275^{* *}$ \\
& $M$ & 20.02 & 1.51 & 1.80 & 5.22 & 3.70 & 4.10 & 3.64 & 4.11 & 3.37 \\
& SD & 1.75 & 0.50 & 1.20 & 2.28 & 0.71 & 0.63 & 0.62 & 0.55 & 0.63 \\
& Skew (SE=.096) & 2.34 & -0.02 & 1.50 & -0.06 & -0.21 & -0.49 & -0.18 & -0.18 & -.321 \\
& Kurt (SE=.192) & 6.52 & -2.01 & 1.21 & -0.73 & -0.25 & 0.39 & -0.26 & -0.43 & .550 \\
\hline
\end{tabular}

$S P$ Social presence, ELO expected learning outcome, LLI learner-learner interactions, LII learnerinstructor interactions, $L C I$ learner-content interactions, $L 2$ Prof. self-rated L2 proficiency from 1 (low) to 10 (high), Online Exp. online English study experience

$* p<.05, * * p<.01$

Structural equation modeling (SEM) was applied using the survey results to test the study's hypotheses. Following suggestions by Hair et al. (2006), the mediating effect of learner interaction on the relationship between social presence and learning outcome were identified. Before testing the hypothesized model, the study needed to validate the latent constructs for reliability, validity, and unidimensionality. A fivefactor correlated model was used to validate the five variables in the hypothesized model. The maximum-likelihood method with Varimax rotation was used to extract factors for the components. Unidimensionality was confirmed for the five factors, however, learner-instructor interactions produced an average variance extracted (AVE) score below the recommended value of 0.50 (Fornell \& Larcker, 1981). Even though the AVE scores for learner-learner and learner-content factors were below 0.50 , composite reliability scores were all above the recommended 0.60 level which provided sufficient evidence to go forth with testing the proposed model.

\section{Results}

Table 2 displays mean scores and Pearson correlation results for the variables of interest. Regarding demographics, females reported higher levels of learner-learner and learner-content interactions than males, and older students showed to be slightly more willing to interact with their instructors. Females also reported slightly higher levels of L2 proficiency and expected learning outcome. L2 proficiency revealed a positive correlation with learner-learner interactions. Further, students reporting higher levels of L2 proficiency also reported to have higher learning outcome 
beliefs. Older students had more experience with online classes which was expected since sophomores were exposed to the online videoconference classes when classes were first moved online in the spring semester of 2020, while younger freshmen students began classes the third semester of online classes in the spring of 2021.

Regarding the interaction variables, students reported learner-instructor interactions the most, followed by learner-learner and then learner-content interactions. Overall, students considered themselves to have high levels of expected learning outcome. Pearson correlations among the variables of interest were statistically significant.

\section{Confirmatory factor analysis}

Carrying out a confirmatory factor analysis (CFA) was the next step in testing for possible mediation effects as well as identifying path coefficients within the proposed model. Initially, several reiterations of applying recommendations from modification indices were identified due to insufficient model fit. Once satisfactory fit was achieved, the hypothesized model was tested using structural equation modeling. The result of CFA was $X^{2}=952.45 ; \mathrm{df}=306 ; p<0.001 ; \mathrm{CMIN} / \mathrm{df}=2.665$; $\mathrm{RMSEA}=0.051$; NFI $=0.951 ; \mathrm{CFI}=0.943$; $\mathrm{IFI}=0.943$; $\mathrm{PCLOSE}=0.382$, indicat ing adequate model fit was achieved.

The mediation model was next tested and path coefficients are seen in Fig. 2. Table 3 displays the direct and indirect path coefficients. The relationship between social presence and self-efficacy of learning expectations was completely removed after adding the three interaction sub-components, indicating full mediation. Social presence

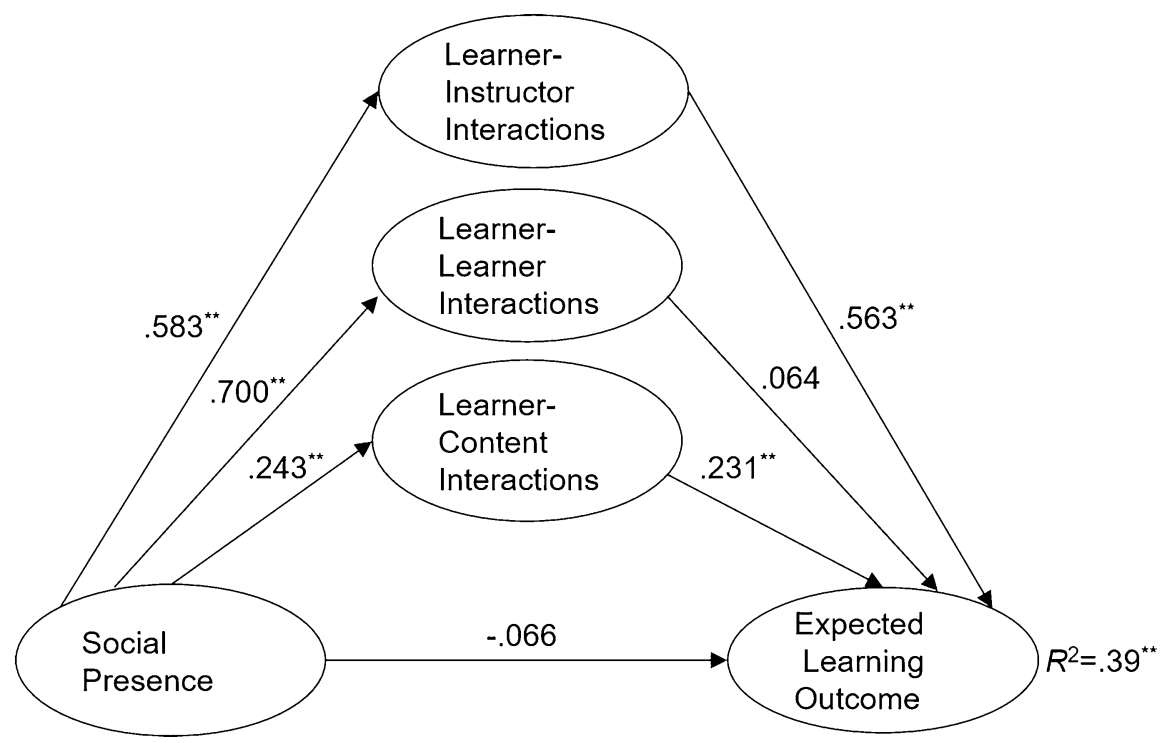

Fig. 2 Final mediation model 
Table 3 Path coefficients for direct and indirect relationships

\begin{tabular}{llllll}
\hline & $\beta$ & S.E & C.R & Beta & $p$ \\
\hline $\begin{array}{l}\text { Direct path } \\
\text { SP LII }\end{array}$ & & & & & \\
SP $\rightarrow$ LCI & .362 & .030 & 12.095 & .584 & $.000^{* *}$ \\
SP $\rightarrow$ LLI & .192 & .034 & 5.579 & .243 & $.000^{* *}$ \\
LLI $\rightarrow$ ELO & .396 & .037 & 10.710 & .700 & $.000^{* *}$ \\
LCI $\rightarrow$ ELO & .081 & .083 & .983 & .064 & .325 \\
LII $\rightarrow$ ELO & .211 & .037 & 5.704 & .231 & $.000^{* *}$ \\
SP $\rightarrow$ ELO & .653 & .073 & 8.967 & .536 & $.000^{* *}$ \\
Indirect path & -.048 & .053 & -.901 & -.066 & .368 \\
SP X LII/LCI/LLI X ELO & .309 & & & .430 & $.000^{* *}$ \\
SP X LII X ELO & .236 & & & .328 & $.000^{* *}$ \\
SP X LLI X ELO & .032 & & & .045 & .813 \\
SP X LCI X ELO & .041 & & & .056 & $.000^{* *}$ \\
\hline
\end{tabular}

SP Social presence, ELO expected learning outcome, LLI learnerlearner interactions, LII learner-instructor interactions, LCI learnercontent interactions

$* * p<.01$

produced the highest path coefficients with learner-learner and learner-instructor interactions. Further, learner-instructor interactions and academic learning expectations was twice as large as the path between learner-content interactions and learning expectations. This significantly higher path coefficient indicates greater levels of mediation when learner-instructor interactions was added to the model. Learner-learner interactions showed no relation to expected learning outcome, contributing to no mediation effect. In all, the model explained $39 \%$ of variance $\left(R^{2}=0.39, p<0.001 * *\right)$ of self-efficacy with expected learning outcomes when attending EFL classes with a videoconference component to supplement face-to-face instruction.

In line with expected results, learner-instructor interactions and learner-content interactions had a mediating effect on the relationship between social presence and learning outcome. As students took action to engage the instructor and the class content, the positive relationship between social presence and expected learning outcome was explained. In all, learner-instructor interactions had the greatest mediation effect (i.e., full mediation), followed by partial mediation with learner-content interactions. In the context of videoconference courses, learner-learner interactions appear to have no effect on the relationship between social presence and learning outcome.

\section{Discussion}

Several findings of significance emanated from this study and contribute to the quickly emerging field of research focused on video synchronous courses (de Oliveira \& Esteve-González, 2020; Eslami \& Kung, 2016; Kim, 2014; Lenkaitis, 
2020). The initial review of the study variables revealed that students reported high levels of online interactions, indicating EFL students appeared ready for the demands of emergency remote online classes with a videoconference component due to Covid-19. Further, increased levels of learner interactions, be them with the instructor, other learners, or course content, had a positive effect on expected learning outcome at the bivariate correlational level. Lastly, the mediation model with the three interaction subcomponents helped explain the relationship between social presence and expected learning outcomes in EFL. Mediation analysis indicates learnerinstructor interactions had the largest mediating effect, followed by learner-content interactions. Learner-learner interactions produced no mediation effect as indicated by the null path coefficient between learner-learner interactions and expected learning outcome.

Demographic variables produced a few noteworthy correlations. With increasing L2 proficiency, students reported higher levels of social presence, expected learning outcome, learner-learner interactions, and learner-content interactions. While older students had more experience with online classes, and reported higher levels of L2 proficiency, this did not influence rates of reported learner-learner or learner-content interactions, and only moderately influenced levels of learner-instructor interactions. Regarding gender, females reported slightly higher levels of L2 proficiency and moderately higher levels of learner-learner and learner-content interactions. Moreover, gender showed a slight significant relation with social presence and learning outcome.

Answering research question one (i.e., What are the influences of social presence on expected learning outcome and learner interactions in videoconference courses?) provides initial insight into the variables of interest. The three interaction variables were above the midpoint of 3.5 which suggests the participants generally had positive responses pertaining to engagement with fellow students, the instructor, and course content. The high levels of interactions were recognized for learner-instructor and learner-content interactions, suggesting students, in general, perceive themselves as active participation in online learning during the videoconference courses.

In direct regard to research question one, social presence had a positive influence on expected learning outcome which is in line with past research (Stewart, 2019). Students felt positive about social presence and learning interactions, echoing past findings that sought to better understand this relationship (Akcaoglu \& Lee, 2018). Further, social presence revealed positive path coefficients with each of the three interaction types, however, at different levels. Social presence had a stronger influence on learner-learner and learner-instructor interactions than with learner-content interactions. In all, social presence proved to be an influential factor to learning outcomes within videoconference courses, supporting our empirical understanding of classroom interactions (Hostetter \& Busch, 2013). These results are in particular support of Saadatmand et al.'s (2017) study which recognized that social presence, in terms of developing a sense of belonging to the course community, was perceived to be essential to course outcome beliefs and overall satisfaction. Additionally, findings here are in line with research by Liu et al. (2009) who discovered that students holding high perception levels of social presence display a higher degree of interaction with their classmates, resulting in higher course grades. Results here 
add evidence to the Richardson's (2017) claim that fostering social presence is key when attempting to facilitate increased levels of participation and satisfaction in the context of a videoconference class. Therefore, this study's findings substantiate the proposition that social presence has a positive influence on interactions and expected learning outcomes in fully online EFL videoconference courses with an LMS component.

Concerning research question two (i.e., How do learner interactions mediate the relationship between social presence and expected learning outcome in videoconference courses?), learner interactions distinctly mediated the relationship between social presence and expected learning outcome of students attending videoconference courses. Social presence supported opportunities for interactions and these interactions significantly contributed to learning beliefs. Through mediation analysis, the study found that interactions with the instructor, and to a lesser extent the course content, mediated the relationship between social presence and expected learning outcome.

Findings pertaining to the positive influence social presence has on interactions is consistent with past studies (Oyarzun et al., 2017; Tu \& McIsaac, 2010), and now we see that this relationship is partly described by the types of interactions students have with one another, the instructor, and content. With the EFL students attending videoconference courses, increasing levels of interactions led to increased levels of expected learning outcome, building on Akcaoglu and Lee's (2018) results which revealed the positive influence social presence has on the cognitive and affective aspects of learning. Through mediation analysis, evidence suggests that the relationship between social presence and expected learning outcomes are explained mostly through learner-instructor beliefs, and to a lesser extent through learnercontent interactions. In contrast, learner-learner interactions showed no mediation effect which goes against findings from Kara (2020) and Oyarzun et al. (2017) who reported that learner-learner interactions were evident of improved learning outcomes.

According to the model's final mediation results, learner-learner interactions showed no mediation effect, and this may be attributed to the restrictive nature of videoconferencing courses. With Zoom and WebEx videoconference platforms, learner-learner interactions often occur in private breakout rooms where they can neither be observed or graded if the instructor is in the main conference room. In such learning circumstances, students can either resort to their first language (i.e., Korean) or avoid communicating whatsoever without the instructor knowing. Moreover, when the classroom is together in one videoconference room, only one speaker at a time can talk. In such a sage on the stage context, learners lack opportunity to freely participate with one another in a natural manner, and this decreases the value they may hold towards learner-learner interactions. In other words, the students' social connections with each other do not influence academic outcome because those connections, in the form of conversation or group work, are made outside the view of the instructor.

With the students in the current study, we see that learner-instructor interactions proved to be more influential than either learner-content interactions or learnerlearner interactions. Learner-instructor interactions proved to be most important 
when it came to learning outcome, supporting extant literature highlighting the emphasis on agentic engagement with instructors (Alqurashi, 2019; Bailey et al., 2021). Among the EFL South Korean studnets here, instructor support continues to be the most important when it comes to learning outcome, which is in line with past literature (Kang \& Im, 2013; Richardson et al., 2017). This echoes results from Sebastianelli et al.'s (2015) investigation on the influencing factors of perceived learning and satisfaction which found learner-instructor interaction had a positive impact on satisfaction, and that greater amounts of learner-learner interactions lead to improved learning outcomes (Kara, 2020; Oyarzun et al., 2018).

Findings from this study were in contrast to past studies which suggested (1) social presence did not affect course outcome (Bray et al., 2008), (2) students overestimated the importance of social presence (Oyarzun et al., 2018), and (3) that social presence decreased student performance (Kuo et al., 2014; Oyarzun et al., 2018). These differences are attributed to the different learning environments. In communication courses like conversational English classes, where learner-learner participation is critical for mastering learning goals (e.g., target language communication skills), videoconferencing may be problematic. Disagreeing with classmates in a trusted community of inquiry is not easy for students (Lambert \& Fisher, 2013), and this may be even more true in shared digital classrooms where learner interactions can be recorded and then archived on class learning management systems for future viewing. Consequently, apprehensive students may avoid speaking with one another out of fear of looking foolish or being negatively evaluated. In videoconference courses with a focus on communication training, findings here suggest that social presence is key to positive learning outcomes and those outcomes are distinctly influenced by different types of learner interactions.

\section{Pedagogical implications}

Findings here shine new light on how pedagogical experts approach crafting lessons and activities in the videoconference class. For instance, results indicate instructors should have social interactions in mind when designing videoconference courses to achieve higher levels of learning and course satisfaction. Specific recommendations to heighten social presence include integrating videoconference meetings with features like chat, screen share, and breakout rooms. Multimodal communication made possible through these features stems from multimodal thinking and planning by the instructor.

Non-verbal means of communication and interactions add layers of information density to the classroom meetings. Accordingly, one major recommendation put forward here entails instructors utilize classroom polls and surveys for formative assessment and to collect student input. Moreover, participation when videoconferencing can be facilitated through encouraging the use of combined speech and iconic gestures (e.g., raise hand, thumbs up, and smiley face icons). Further, the chat box provides opportunity for group and individual messaging. In EFL and ESL courses, text messaging in the chat box provides opportunity for pragmatic training through language play (e.g., lol, hehe, OMG) (Bailey \& Almusharrof, 2021). 
The growing need for synchronous online classes continues to increase the demand for videoconference features that cater to educators in virtual classrooms, training sessions and workshops. Currently, educators may wish to consider videoconference platforms a compliment to LMS and not a replacement. LMS like Moodle and Blackboard have decades of research and practice supporting learning specifically. Contrarily, platforms like Zoom and WebEx were originally designed for conference calls with a video component. However, increasing Internet broadband along with quickly evolving set of education-friendly features are closing the gap between pedagogical affordances offered by LMS and videoconference websites. Until then, instructors are urged to share links to their videoconference meetings within an LMS course. In essence, creating a videoconference-enhanceed LMS course which offers activity modules like discussion forums, assignments, and wikis along with videoconference meetings.

In some academic disciplines, such as conversational English classes, the course grade is dependent on learner-learner discourse, opposed to classes with a grading system purely oriented around exams or projects (Crosthwaite et al., 2015). Therefore, in the videoconference learning environment, a variety of learning activities should be provided to support learner-learner interactions. Activity choice directly influences the type of interactions students have with one another. Collaborative projects, group presentations, and conversational English practice are examples of activities that support learner-learner interactions. Further, learner-learner interactions within such activities should be connected to assessment criteria if we want students to engage in more active participation with one another.

In summary, recognizing patterns of influence between social presence and interactions and how those interactions influence academic outcome expectations provide educators insight into the types of activities that support learning in videoconference-based classrooms. Such activities should foster interactions that build a sense of community (Chatterjee \& Correia, 2020; Zhu, 2012) since as the learners' sense of social presence increases so will their interactions with others, leading to positive academic outcome beliefs.

\section{Conclusion}

This study attempted to understand how social presence predicted expected learning outcome beliefs, and how interactions within videoconference-supported EFL courses mediated the relationship between social presence and expected levels of learning outcome. In recent decades, research has confirmed that social presence assists second language acquisition (Lapkin et al., 2002; McDonough, 2004), and now we have new insight in how subcomponents of interactions influence the positive effect of social presence on academic outcomes and perceived learning in the videoconference EFL class. In the matter of establishing a sense of belonging, social presence continues to establish itself as a crucial factor in learning outcomes (Saadatmand et al., 2017), and this holds true in the context of videoconference classes. 
There are some limitations in this study that should be noted. One limitation is that students were asked to self-report their perception of social presence, as well as their level of interactions and perceived learning. In addition, the current study lacks the inclusion of actual performance scores, such as the final class grades or standardized test results, which is a restraint with this type of questionnaire research which uses self-reported learning perceptions as the dependent variable. Moreover, future research should include other means of assessment such as interviews or observations. Further, these findings pertain to South Korean university students. A similar design testing the study's model in different geographical regions and with different age groups would provide more documentation of observed relationships.

This study lays the foundation for future research that includes the teacher, learner, and content presence of the community of inquiry framework. Learnerlearner interactions entails peer communication and is essential for mastering speaking skills, therefore, a lack of peer influence on course outcome should be alarming. Consequently, instructors, curriculum designers, educational researchers, and other pedagogical experts are advised to direct more attention on methods to promote and report on observable (i.e., measurable) learner-learner interactions in the videoconference classroom. Assessment must reflect videoconference-supported actions because students are reactive to how they are graded and behave accordingly. Without incentives to interact with one another, such interactions are less likely to occur.

Acknowledgements This paper was supported by Konkuk University Glocal Campus in 2021.

\section{Declarations}

Conflict of interest The author declare no conflict of interest.

\section{References}

Akcaoglu, M., \& Lee, E.-B. (2018). Using Facebook groups to support social presence in online learning. Distance Education, 39(3), 334-352. https://doi.org/10.1080/01587919.2018.1476842

Alqurashi, E. (2019). Predicting student satisfaction and perceived learning within online learning environments. Distance Education, 40(1), 133-148. https://doi.org/10.1080/01587919.2018.1553562

Alavi, M., Marakas, G. M., \& Yoo, Y. (2002). A comparative study of distributed learning environments on learning outcomes. Information Systems Research, 13(4), 404-415. https://www.jstor.org/stable/ 23015721

Artino, A. R., \& McCoach, D. B. (2008). Development and initial validation of the online learning value and self-efficacy scale. Journal of Educational Computing Research, 38(3), 279-303. https://doi. org/10.2190/EC.38.3.c

Bailey, D. R., \& Almusharraf, N. M. (2021). Facebook in class: The instructor's influence on engagement and language play in online social media forums. Computer Assisted Language Learning - Electronic Journal, 22(3), 66-85.

Bailey, D. R., Almusharraf, N. M., \& Hatcher, R. (2021). Finding satisfaction: Intrinsic motivation for synchronous and asynchronous communication in the online language learning context. Education and Information Technology, 26, 2563-2583. https://doi.org/10.1007/s10639-020-10369-z

Baker, K. Q., \& Moyer, D. M. (2018). The relationship between students' characteristics and their impressions of online courses. American Journal of Distance Education, 33(1), 16-28. https://doi.org/10. 1080/08923647.2019.1555301

Bandura, A. (1997). Self-efficacy: The exercise of control. Freeman. 
Bernard, R. M., Abrami, P. C., Borokhovski, E., Wade, C. A., Tamim, R. M., Surkes, M. A., et al. (2009). A meta-analysis of three types of interaction treatments in distance education. Review of Educational Research, 79, 1243-1289. https://doi.org/10.3102/0034654309333844

Bolton, K. (2008). English in Asia, Asian Englishes, and the issue of proficiency. English Today, 24(2), 3-12. https://doi.org/10.1017/S026607840800014X

Bong, M., \& Skaalvik, E. M. (2003). Academic self-concept and self-efficacy: How different are they really? Educational Psychology Review, 15(1), 1-40. https://doi.org/10.1023/A:1021302408382

Bray, E., Aoki, K., \& Dlugosh, L. (2008). Predictors of learning satisfaction in Japanese online distance learners. International Review of Research in Open and Distance Learning, 9(3), 1-24. https://doi. org/10.19173/irrodl.v9i3.525

Chatterjee, R., \& Correia, A. P. (2020). Online students' attitudes toward collaborative learning and sense of community. American Journal of Distance Education, 34(1), 53-68. https://doi.org/10.1080/ 08923647.2020.1703479

Ching, Y. H., \& Hsu, Y. C. (2013). Collaborative learning using Voice Thread in an online graduate course. Knowledge Management \& E-Learning: An International Journal, 5(3), 298-314. https:// doi.org/10.34105/j.kmel.2013.05.021

Cortese, J., \& Seo, M. (2012). The role of social presence in opinion expression during FtF and CMC discussions. Communication Research Reports, 29, 44-53. https://doi.org/10.1080/08824096.2011. 639913

Crosthwaite, P. R., Bailey, D. R., \& Meeker, A. (2015). Assessing in-class participation for EFL: Considerations of effectiveness and fairness for different learning styles. Language Testing in Asia, 5(9), 1-18. https://doi.org/10.1186/s40468-015-0017-1

de Oliveira, J. M., \& Esteve-González, V. (2020). Navigating choppy discourses: A conceptual framework for understanding synchronous text-based computer-mediated communication. Text \& Talk, 40(2), 171-193. https://doi.org/10.1515/text-2020-2056

Dennen, V. P., Darabi, A. A., \& Smith, L. J. (2007). Instructor-learner interaction in online courses: The relative perceived importance of particular instructor actions on performance and satisfaction. Distance Education, 28(1), 65-79. https://doi.org/10.1080/01587910701305319

Ding, Y. (2020). What constitutes an effective instructional video?: Perspectives from Chinese EFL learners. In B. Zou \& M. Thomas (Eds.), Recent developments in technology-enhanced and computerassisted language learning (pp. 236-256). IGI Global. https://doi.org/10.4018/978-1-7998-1282-1. ch011

Eslami, Z. R., \& Kung, W. T. (2016). Focus-on-form and Efl learners' language development in synchronous computer-mediated communication: Task-based interactions. The Language Learning Journal, 44(4), 401-417. https://doi.org/10.1080/09571736.2016.1227219

Fornell, C., \& Larcker, D. F. (1981). Evaluating structural equation models with unobservable variables and measurement error. JMR Journal of Marketing Research, 18(1), 39-50. https://doi.org/10.1177/ 002224378101800104

Gameel, B. G. (2017). Learner satisfaction with massive open online courses. American Journal of Distance Education, 31(2), 98-111. https://doi.org/10.1080/08923647.2017.1300462

Garrison, D. R. (2017). E-learning in the 21st century: A community of inquiry framework for research and practice. Taylor \& Francis.

Garrison, D. R., \& Vaughan, N. D. (2008). Blended learning in higher education: Framework, principles, and guidelines. Wiley.

George, D., \& Mallery, M. (2010). SPSS for Windows step by step: A simple guide and reference, 17.0 update (10th ed.) Pearson.

Giannopoulos, E., Eslava, V., Oyarzabal, M., Hierro, T., González, L., Ferre, M., \& Slater, M. (2008). The effect of haptic feedback on basic social interaction within shared virtual environments. In $\mathrm{M}$. Ferre (Ed.), Proceedings of the 6th international conference on haptics: Perception, devices and scenarios (pp. 301-307). Springer. https://doi.org/10.1007/978-3-540-69057-3

Grandzol, C. J., \& Grandzol, J. R. (2010). Interaction in online courses: More is not always better. Online Journal of Distance Learning Administration, 13(2), 1-18. https://eric.ed.gov/?id=EJ895996

Hair, J. F., Black, W. C., Babin, B. J., Anderson, R. E., \& Tatham, R. L. (2006). Multivariate data analysis. Pearson Prentice Hall.

Hostetter, C., \& Busch, M. (2006). Measuring up online: The relationship between social presence and student learning satisfaction. Journal of Scholarship of Teaching and Learning,6(2), 1-12. https:// eric.ed.gov/?id=EJ854921 
Jin, S. A. (2010). Parasocial interaction with an Avatar in second life: A typology of the self and an empirical test of the mediating role of social presence. Presence, 19(4), 331-340. https://doi.org/10. 1162/PRES_a_00001.

Kang, M., \& Im, T. (2013). Factors of learner-instructor interaction which predict perceived learning outcomes in online learning environment. Journal of Computer Assisted Learning, 29(3), 292-301. https://doi.org/10.1111/jcal.12005

Kara, M. (2020). Distance education: A systems view of online learning. Educational Review. https://doi. org/10.1080/00131911.2020.1766204

Kaul, M., Maija, A., \& Xiaomeng, W. (2018). Dynamics of the Community of Inquiry (CoI) within a Massive Open Online Course (MOOC) for In-Service Teachers in Environmental Education. Education Sciences, 8(2), 40. https://doi.org/10.3390/educsci8020040

Kim, H. Y. (2014). Learning opportunities in synchronous computer-mediated communication and faceto-face interaction. Computer Assisted Language Learning, 27(1), 26-43. https://doi.org/10.1080/ 09588221.2012.692386

Kim, K.-J., Park, E.-I., \& Sundar, S. S. (2013). Caregiving role in human-robot interaction: A study of the mediating effects of perceived benefit and social presence. Computers in Human Behavior, 29(4), 1799-1806. https://doi.org/10.1016/j.chb.2013.02.009

Kim, J.-Y., Song, H.-Y., \& Luo, W. (2016). Broadening the understanding of social presence: Implications and contributions to the mediated communication and online education. Computers in Human Behavior, 65, 672-679. https://doi.org/10.1016/j.chb.2016.07.009

Kim, M.-K., \& Ketenci, T. (2019). Learner participation profiles in an asynchronous online collaboration context. Internet Higher Education, 41, 62-76. https://doi.org/10.1016/j.iheduc.2019.02.002

Krashen, S. (1982). Principles and practice in second language acquisition. Pergamon Press.

Kuo, Y. C., Walker, A., Belland, B. R., \& Schroder, K. E. E. (2013). A predictive study of student satisfaction in online education programs. International Review of Research in Open and Distance Learning, 14(1), 16-39. https://doi.org/10.19173/irrodl.v14i1.1338

Kuo, Y. C., Walker, A., Schroder, K. E. E., \& Belland, B. R. (2014). Interaction, Internet self-efficacy, and self-regulated learning as predictors of student satisfaction in online education courses. Internet and Higher Education, 20, 35-50. https://doi.org/10.1016/j.iheduc.2013.10.001

Lambert, J. L., \& Fisher, J. L. (2013). Community of inquiry framework: Establishing community in an online course. Journal of Interactive Online Communication, 12(1), 1-16. https://www.learntechlib. $\mathrm{org} / \mathrm{p} / 153507 /$.

Lenkaitis, C. A. (2020). Technology as a mediating tool: Videoconferencing, L2 learning, and learner autonomy. Computer Assisted Language Learning, 33(5-6), 483-509. https://doi.org/10.1080/ 09588221.2019.1572018

Liu, S. Y., Gomez, J., \& Yen, C.-J. (2009). Community college online course retention and final grade: Predictability of social presence. Journal of Interactive Online Learning, 8(2), 165-182. https://eric. ed.gov/?id=EJ938828

Ishtaiwa, F. F., \& Aburezeq, I. M. (2015). The impact of Google Docs on student collaboration: A UAE case study. Learning, Culture and Social Interaction, 7, 85-96. https://doi.org/10.1016/j.1csi.2015. 07.004

Lapkin, S., Swain, M., \& Smith, M. (2002). Reformulation and the learning of French pronominal verbs in a Canadian French immersion context. Modern Language Journal, 86(4), 485-507. https://doi. org/10.1111/1540-4781.00157

Lowenthal, P. R., \& Dunlap, J. C. (2018). Investigating students' perceptions of instructional strategies to establish social presence. Distance Education, 39(3), 281-298. https://doi.org/10.1080/01587919. 2018.1476844

McDonough, K. (2004). Learner-learner interaction during pair and small group activities in a Thai EFL context. System, 32(2), 207-224. https://doi.org/10.1016/j.system.2004.01.003

Michel, M., \& Cappellini, M. (2019). Alignment during synchronous video versus written chat L2 interactions: A methodological exploration. Annual Review of Applied Linguistics, 39, 189-216. https:// doi.org/10.1017/S0267190519000072

Moore, M. G. (1989). Three types of interaction. American Journal of Distance Education, 3(2), 1-7. https://doi.org/10.1080/08923648909526659

Oncu, S., \& Ozdilek, Z. (2013). Learning with peers: an interdisciplinary comparative study of learner interaction and satisfaction on an instructional design course. Educational Sciences: Theory and Practice, 13(2), 1251-1261. https://eric.ed.gov/?id=EJ1017273 
Oyarzun, B., Barreto, D., \& Conklin, S. (2018). Instructor social presence effects on learner social presence, achievement, and satisfaction. TechTrends, 62(6), 625-634. https://doi.org/10.1007/ s11528-018-0299-0

Oyarzun, B., Stefaniak, J., Bol, L., \& Morrison, G. R. (2017). Effects of learner-to-learner interactions on social presence, achievement and satisfaction. Journal of Computing in Higher Education, 30(1), 154-175. https://doi.org/10.1007/s12528-017-9157-x

Ouyang, F., \& Chang, Y. H. (2019). The relationships between social participatory roles and cognitive engagement levels in online discussions. British Journal of Educational Technology, 50(3), 13961414. https://doi.org/10.1111/bjet.12647

Pintrich, P. R., Smith, D. A. F., Garcia, T., \& McKeachie, W. J. (1993). Reliability and predictive validity of the Motivation Strategies for Learning Questionnaire (MSLQ). Educational and Psychological Measurement, 53, 801-813. https://doi.org/10.1177/0013164493053003024

Rakushin-Lee, A. (2021). Breaking through digital barriers: Exploring EFL students' views of Zoom breakout room experiences. Korean Journal of English Language and Linguistics, 21, 510-524. https://doi.org/10.15738/kjell.21.202106.510

Rassaei, E. (2017). Video chat vs. face-to-face recasts, learners' interpretations and L2 development: A case of Persian EFL learners. Computer Assisted Language Learning, 30(1-2), 133-148. https://doi. org/10.1080/09588221.2016.1275702

Richardson, J. C., Maeda, Y., Lv, J., \& Caskurlu, S. (2017). Social presence in relation to students' satisfaction and learning in the online environment: A meta-analysis. Computers in Human Behavior, 71, 402-417. https://doi.org/10.1016/j.chb.2017.02.001

Robertson, M. K., \& Piotrowski, A. (2019). Authentic inquiry with undergraduate preservice teachers in synchronous interactive video conferencing courses. In J. Yoon \& P. Semingson (Eds.), Educational technology and resources for synchronous learning in higher education (pp. 109-128). IGI Global. https://doi.org/10.4018/978-1-5225-7567-2.ch006

Rockinson-Szapkiw, A. J., Wendt, J., Wighting, M., \& Nisbet, D. (2016). The predictive relationship among the community of inquiry framework, perceived learning and online, and graduate students' course grades in online synchronous and asynchronous courses. International Review of Research in Open and Distributed Learning, 17(3), 18-35. https://doi.org/10.19173/irrodl.v17i3.2203

Rovai, A. P. (2002). Development of an instrument to measure classroom community. Internet and Higher Education, 5(3), 197-211. https://doi.org/10.1016/S1096-7516(02)00102-1

Rubin, J. (1975). What the "good language learner" can teach us. TESOL Quarterly, 9(1), 41-51. https:// doi.org/10.2307/3586011

Saadatmand, M., Uhlin, L., Hedberg, M., Åbjörnsson, L., \& Kvarnström, M. (2017). Examining learners' interaction in an open online course through the community of inquiry framework. European Journal of Open, Distance and E-Learning, 20(1), 61-79. https://doi.org/10.1515/eurodl-2017-0004

Sebastianelli, R., Swift, C., \& Tamimi, N. (2015). Factors affecting perceived learning, satisfaction, and quality in the online MBA: A structural equation modeling approach. Journal of Education for Business, 90(6), 296-305. https://doi.org/10.1080/08832323.2015.1038979

Shackelford, J. L., \& Maxwell, M. (2012). Sense of community in graduate online education: Contribution of learner to learner interaction. International Review of Research in Open \& Distance Learning, 13(4), 228-249. https://doi.org/10.19173/irrodl.v13i4.1339

Song, H., Kim, J., \& Luo, W. (2016). Teacher-student relationship in online classes: A role of teacher self-disclosure. Computers in Human Behavior, 54, 436-443. https://doi.org/10.1016/j.chb.2015.07. 037

Stewart, M. K. (2019). The community of inquiry survey: An assessment instrument for online writing courses. Computers and Composition, 52, 37-52. https://doi.org/10.1016/j.compcom.2019.01.001

Swain, M. (1985). Communicative competence: Some roles of comprehensible input and comprehensible output in its development. In S. M. Gass \& C. G. Madden (Eds.), Input in second language acquisition (pp. 235-253). Newbury House.

Swain, M., \& Lapkin, S. (1998). Interaction and second language learning: Two adolescent French immersion students working together. The Modern Language Journal, 82(3), 320-337. https://doi. org/10.1111/j.1540-4781.1998.tb01209.x

Tabachnick, B. G., \& Fidell, L. S. (2001). Using multivariate statistics (4th ed.). Allyn \& Bacon.

Tu, C. H., \& McIsaac, M. S. (2010). The relationship of social presence and interaction in online classes. The American Journal of Distance Education, 16(3), 131-150. https://doi.org/10.1207/S15389286A JDE1603_2 
Ubon, N. A., \& Kimble, C. (2003). Supporting the creation of social presence in online learning communities using asynchronous text-based CMC. In Proceedings of the 3rd international conference on technology in teaching and learning in higher education, July 2003, Heidelberg, Germany (pp. 295-300).

Wright, R. J., Martland, J., Stafford, A. K., \& Stanger, G. (2006). Teaching number: Advancing children's skills and strategies (2nd ed.). Paul Chapman Publishing Ltd.

Vygotsky, L. S. (1978). Mind in society: The development of higher psychological Processes. Harvard University Press.

Zhu, C. (2012). Student satisfaction, performance, and knowledge construction in online collaborative learning. Educational Technology \& Society, 15(1), 127-136.

Publisher's Note Springer Nature remains neutral with regard to jurisdictional claims in published maps and institutional affiliations.

Daniel Bailey holds a Ph.D. in Education Technology from Korea University and works as an assistant professor in Konkuk University's Department of English Language Culture. He is a passionate teacher who cares deeply about helping students stay motivated and connected. Daniel's pedagogical interests lie in technology-rich curriculum development. His research interests pertain to motivation psychology, learning technology, formative assessment, and VR/AR assisted learning. In addition to these research interests, Daniel regularly publishes on the subject of online communication and multimedia-assisted language learning. 